\title{
Resolution of Deep Disagreement: Not Simply Consensus
}

\author{
LEAH HENDERSON
}

Department of Theoretical Philosophy

University of Groningen

9700 AB Groningen PO Box 72

The Netherlands

l.henderson@rug.nl

\begin{abstract}
Robert Fogelin has argued that in deep disagreements, resolution cannot be achieved by rational argumentation. In response, Richard Feldman has claimed that deep disagreements can be resolved in a similar way to more everyday disagreements. I argue that Feldman's claim is based on a relatively superficial notion of "resolution" of a disagreement whereas the notion at stake in Fogelin's argument is more substantive. Furthermore, I argue that Feldman's reply is based on a particular reading of Fogelin's argument. There is an alternative reading, which takes the central concern to be the role of common ground in argumentation. Engaging with this version of Fogelin's argument is also a worthwhile endeavour.
\end{abstract}

Résumé: Robert Fogelin a soutenu que dans les désaccords profonds, on ne peut pas obtenir une resolution par une argumentation rationnelle. En réponse, Richard Feldman a affirmé qu'on peut résoudre des désaccords profonds de la même manière que les désaccords quotidiens. Je soutiens que l'affirmation de Feldman est basée sur une notion relativement superficielle de «résolution» d'un désaccord alors que la notion en jeu dans l'argument de Fogelin est plus substantielle. En outre, j'affirme que la réponse de Feldman se fonde sur un type particulier d'interprétation de l'argument de Fogelin. Il existe une interprétation alternative, dont la préoccupation centrale est le rôle du terrain d'entente dans l'argumentation. S'engager avec cette version de l'argument de Fogelin est également un effort valable.

Keywords: deep disagreement, Fogelin, Feldman, suspension of judgment, consensus, common ground 


\section{Introduction}

What should the role of rational argumentation be in addressing the deepest disagreements that arise in our society? Robert Fogelin has argued for the rather pessimistic conclusion that deep disagreements cannot be resolved by rational arguments (Fogelin 1985). If he is right, this would have significant implications for how deep disagreements should be approached. In particular, it might be thought that an emphasis on exchanging reasons and arguments may sometimes be misplaced, or even, as some have suggested, "dangerous" (Campolo 2005).

A number of authors have concurred with Fogelin's pessimism about the scope of rational argumentation in resolving deep disagreements (Campolo 2005; Turner 2005; Godden 2010; Barris 2018). But there has been considerable resistance to Fogelin's argument from those who are more optimistic (Lugg 1986; Memedi 2007; Phillips 2008; Siegel 2013; Aikin 2018b; Ranalli 2018a). I will focus here on the widely cited optimistic reply given by Richard Feldman (Feldman 2005). Feldman argues that Fogelin's reasons for thinking that deep disagreements cannot be rationally resolved are not strong. His view is based on his evidentialist programme in epistemology. He thinks that deep disagreements, no less than more everyday disagreements, should be resolved according to the evidence. In some cases, he says, the proper resolution will be that both parties suspend judgment on the issue.

Fogelin's short paper has given rise to two interesting, but somewhat different, interpretations. This is because his reasons for pessimism can be understood in one of two main ways. One way of understanding the problem is that deep disagreements involve deeply held "framework principles," which, by their nature, make rational argumentation impossible. This is the way Fogelin's argument has tended to be interpreted in the epistemology community. Another interpretation is that Fogelin is claiming that rational argumentation can become impossible because the participants in a deep disagreement lack common ground. This is the way scholars in argumentation theory have tended to read the argument. 
Feldman's reply is based on the first type of interpretation of Fogelin. Feldman rejects the idea that framework propositions present any unusual difficulty for rational argumentation. This point of view is shared by several other authors who have explored in detail the question of whether there is a way to interpret framework propositions such that they present a compelling obstacle to rational argument (Lynch 2010; Siegel 2013; Pritchard 2018; Ranalli 2018b, 2018a; Siegel 2019). This has led to useful insights into Wittgensteinian hinge epistemology as well as the status of fundamental epistemic principles.

I do not plan to enter this discussion here. Rather I will raise a different kind of difficulty for Feldman's reply, drawing on some ideas from Isaac Levi. I will argue that Feldman is making use of a notion of "resolution" of a disagreement which is different from the more substantive notion which is at stake in Fogelin's argument. The consequence of this is that his response largely fails to engage with Fogelin's argument.

In the final part of the paper, I argue that the way Fogelin's argument has been read by argumentation theorists, according to whom the problem is lack of common ground, is also a compelling interpretation. Understood in this way, Fogelin's argument raises substantive issues, which some replies to Fogelin have already explored. In section 6, I try to indicate where the interesting issues raised by this version of Fogelin's argument really lie.

\section{Fogelin's argument}

Robert Fogelin has put forward a skeptical position about the power of informal logic and critical thinking to resolve disagreements (Fogelin 1985). In particular, he suggests, there are some disagreements that are "deep" and fail to be resolvable by rational argumentation or any rational means. He puts the point as follows:

if deep disagreements can arise, what rational procedures can be used for their resolution? The drift of this discussion leads to the answer NONE (Fogelin 1985, p. 9).

What makes a disagreement "deep"? According to Fogelin, in a deep disagreement, the parties involved disagree at a profound 
level over "framework propositions" in the Wittgensteinian sense. These framework propositions, he claims, are deeply enmeshed in a whole system of mutually supporting propositions (and paradigms, models, styles of acting and thinking) that constitute, if I may use the phrase, a form of life (Fogelin 1985, p. 9).

As an example, he offers the case of abortion, where disagreement centres around the moral status of the foetus. The idea that the foetus has a certain relevant kind of personhood, he suggests, is often grounded in a much broader tradition of religious belief, which involves many other commitments. This broader network of beliefs and commitments may not be shared with those who deny the foetus has such a status.

Fogelin claims that argumentative exchange is "normal" when "it takes place within a context of broadly shared beliefs and preferences' (Fogelin 1985, p. 6). He further insists on the existence of "shared procedures for resolving disagreements" (Fogelin 1985 , p. 8). Fogelin conceives of argument as a kind of practice, rather than simply the exchange of "a structure on propositions" (Fogelin 1985, p. 5). It is an activity situated in a context, rather than an exercise in producing sequences of premises followed logically by conclusions. Thus, his reason for insisting that shared beliefs are necessary is not simply that they would provide a source of agreed premises in the exchange of logical arguments. Rather, the reasons he gives for the reliance on shared assumptions are based on an examination of how argumentative practice tends to work. He gives as an example a simple case from suburban life (Fogelin 1985, p. 5). Suppose parties argue over which road to take home after doing the shopping. The arguments that will be given rely on many shared assumptions. For example, the argument that "I want to pick up the fish last" is only possible, he points out, if the "parties share a great many beliefs and (if this is different) a great many preferences," such as "detailed knowledge of local geography" and preference "for fresh fish over stinking fish." Fogelin says

An important feature of these shared beliefs and preferences is that they lie in the background, unmentioned. They guide the discussion, but they are not the subject of it" (Fogelin 1985, p. 5). 
It might seem that, in ordinary cases like these, if it turns out that the disagreeing parties do have different epistemic attitudes towards some of these background presuppositions, this may well come out in the course of the discussion. For example, it may emerge that one person actually has made a mistake about the geography or thinks the roadworks are still present, when they have actually already gone. There will then be argument over those background propositions as well. None of this would be very unusual.

Fogelin's thesis is that "deep disagreements cannot be resolved through the use of argument, for they undercut the conditions essential to arguing" (Fogelin 1985, p. 8). In a deep disagreement, the context becomes less normal, and thus argument becomes impossible, because the "conditions for argument do not exist" (Fogelin 1985, p. 7).

The language of argument may persist, but it becomes pointless since it makes an appeal to something that does not exist: a shared background of beliefs and preferences (Fogelin 1985, p. 7).

Those who have a deep disagreement then lack the shared background required to make argument work.

One way that Fogelin characterises deep disagreements is as involving a "clash of framework propositions" (Fogelin 1985, p. 8). These lie in the background of the debate, but one might think that: "The way to put the debate on a rational basis is to surface these background propositions and then discuss them directly" (Fogelin 1985, p. 8).

According to this point of view, the framework propositions could be treated just like any other shared presupposition of an argument. They could be hauled into the light of rational scrutiny and argued over. Then there would be nothing in principle to stop the argument being resolved by this process.

Fogelin expresses skepticism about the prospects for doing this. He gives two reasons. First, he points to the deep entanglement of the disputed propositions in a whole "form of life" (Fogelin 1985, p. 9). As a second reason, Fogelin quotes Wittgenstein's skeptical remarks in On Certainty where he worries about how far one can go with reasons in convincing someone who does not share the same "grounds" as oneself (Fogelin 1985, p. 9). Thus, Fogelin 
invokes the Wittgensteinian idea that there may be some commitments which are held without reason and not treated as available as a subject for rational debate. As we will see later, these two different kinds of reasons that Fogelin offers have been developed into two different interpretations of his argument: one which focuses on the lack of common ground between parties engaged in different forms of life (the "common ground reading" of section 5), and one which one which focuses on the role of framework propositions as potentially outside the scope of rational evaluation (the "framework propositions reading" of section 3).

\section{Feldman's reply}

Richard Feldman has argued against Fogelin's view that deep disagreements cannot be rationally resolved. His response to Fogelin's argument has two aspects. He first offers a positive account of how rational resolution works in normal (non-deep) disagreements. He then argues that deep disagreements can be resolved in a similar manner to normal disagreements. He resists Fogelin's idea that there is something particularly problematic about deep disagreements.

Feldman presents the following picture of how rational resolution works in normal disagreements. A rational resolution, he says, arises as a rational response to an exchange of "arguments and evidence." It "[results] from the use of the methods and techniques of rational thought" (Feldman 2005, p. 15). Feldman gives the following rough characterisation of these methods:

[They are] the methods typically developed in critical thinking courses. For present purposes we need not worry about exactly what they include. It is enough to note that they include the use of arguments and the logical analysis of evidence. They do not include the use of threats, force intimidation, bribes, stirring musical themes, and the host of things many of us warn out students to look out for. Roughly, they do not include much of what we find in advertising and politics (Feldman 2005, p. 15).

At each stage in the argumentative process, Feldman argues, there is a rational evaluation of evidence that each person can make. This is spelled out in terms of the evidentialism to which Feldman 
is committed. The evidentialist thesis about justification states that:

A person $S$ is justified in holding doxastic attitude $d$ towards proposition $p$ at time $t$ iff $S$ 's evidence for $p$ at $t$ supports one's taking $d$ towards $p$.

In particular, the attitude of belief is justified when the evidence on balance supports $p$, disbelief is justified when the evidence goes against $p$, and suspension of judgment is justified when the evidence is neutral (Feldman 2009, p. 294).

Feldman combines the evidentialist thesis with the idea that disagreement constitutes a kind of evidence about the disputed proposition. For example, in a case of peer disagreement, he thinks one should subscribe to the following claim: "The proposition that $S$ 's peer who shares $S$ 's evidence concerning $p$ disbelieves $p$ is evidence against $p$ " (Feldman 2009, p. 298).

This means that when you learn of that a peer disagrees with you about $p$, you get evidence against $p$. Putting the evidence of disagreement together with your initial evidence for $p$ may result in a situation where the evidence is balanced between the two sides. Then the rational response would be to suspend judgment. However, there may also be situations where one had initially such strong evidence for $p$ that the total evidence still tells in favour of $p$, even after discovering the disagreement. Furthermore, if the party we disagree with is not a peer, their opinion can still have evidential significance for us, though how much will depend on the details of the situation (Feldman 2009, p. 301).

The assessment of what the evidence best supports can be made at any stage in a disagreement. Feldman gives particular attention to two extremes (Feldman 2006a). On the one hand, one can consider the case of "isolation," where you and your counterpart have both examined the same evidence and arrived at your own conclusions. On the other hand, one can also consider the stage of "full disclosure," where the two sides have "thoroughly discussed the issues. They know each other's reasons and arguments and that the other person has come to a competing conclusion after examining the same information" (Feldman 2006a, p. 220). There are also all the possible stages in between these two extremes.

(C) Leah Henderson Informal Logic, Vol. 40, No. 3 (2020), pp. 359-382 
Feldman says that a disagreement has a "rational resolution available" when there are "some arguments and evidence which could be put forward to which the rational response is agreement" (Feldman 2005, p. 16). In some cases, he says, there will be a resolution of a disagreement "if two people begin by disagreeing about something and then one person comes round to the other's point of view." If this happens on the basis of the presentation of arguments and evidence, then this counts as a "rational resolution" of the disagreement. Feldman argues that this is not the only way a rational resolution may be achieved. Another possibility is that both parties suspend judgment about the issue in question. Feldman contends that in some disagreements, the rational response may be suspension of judgment.

Feldman draws an important distinction between what he calls resolving disagreement and resolving the issue:

when people suspend judgment they have not resolved the issue. That is, they have not come to an agreed conclusion about it. It is left open. But they have overcome their disagreement. Proposition $p$ is no longer something about which they have different beliefs. They have resolved their disagreement (Feldman 2005, p. 17).

Suspending judgment may be the rational resolution of a normal disagreement, for example, where there is no information available which would be capable of resolving the issue (Feldman 2005, pp. 17-18).

Feldman then argues that this picture of how resolution can be achieved in normal disagreements can be extended to cases of deep disagreement. He denies Fogelin's claim that there is something different about these cases. Feldman takes the involvement of framework propositions to be the central point of Fogelin's negative argument. Thus, he understands Fogelin's argument as something like the following:

1. Deep disagreements involve clashes of framework propositions.

2. Disagreements over framework propositions are rationally irresolvable.

C. Deep disagreements are rationally irresolvable. 
Let us call this a "framework proposition reading" of Fogelin's argument. We will see later (section 5) that it is not the only way to read the argument.

Feldman then focuses on providing arguments against premise 2. He allows that framework propositions are "difficult to argue about" (Feldman 2005, p. 19), but he denies that it is impossible to do so. He first says what he thinks Fogelin's case for premise 2 is:

The case for thinking that rational argument cannot resolve a disagreement about a framework proposition apparently depends upon Fogelin's claim that framework propositions are not supported by other individual propositions but instead are in some way connected to systems of propositions, or to "paradigms, models and styles of acting and thinking" (Feldman 2005, p. 19).

In response, Feldman suggests that "evidence" can be understood very broadly, so that it includes whatever factors Fogelin is referring to, though he adds "I must admit, however, that I am not clear about just what he means. I do not know what "styles of acting and thinking he has in mind" (Feldman 2005, p. 19).

Feldman goes on to consider three possible reasons why framework propositions might be regarded as raising particular difficulties, and rejects them all (Feldman 2005, pp. 19-22). He argues that the problem cannot be that the two sides have private evidence which they cannot communicate to one another. Nor does he think that the failure to resolve the disagreement can be attributed to the existence of different reasonable responses to the same evidence. Finally, he rejects the view that "framework propositions are somehow beyond rational assessment." Even if they were, he says, there would still be a rational resolution in the form of suspending judgment, because this would be a situation where one might be able to see that there are alternative framework propositions that give rise to different beliefs. If there is no rational argument for one's own framework propositions as opposed to those of one's opponent, then suspension of judgment should be the required rational response. 


\section{The limits of Feldman's reply}

In the following, I will argue that the notion of resolution of disagreement that Feldman appeals to in his positive argument is not the same as the one which is at stake in Fogelin's argument. Feldman uses a notion of resolution purely in terms of consensus whereas a stronger notion of achieving substantial common ground is at issue in Fogelin's argument (section 4.1). As we shall see, this means that his argument largely fails to engage with Fogelin's point.

Feldman interprets Fogelin's argument according to a framework proposition reading. That is, he takes Fogelin's point about rational irresolvability of deep disagreement to stem from some special status which Fogelin attributes to framework propositions. I am not going to take issue here with Feldman's arguments against the claim that framework propositions present a special problem for resolving disagreements. This is a large issue, which depends on the details of how exactly framework propositions are understood. A number of other authors have also subscribed to a framework propositions reading of Fogelin. The argument has then been developed in two main ways. On the one hand, some philosophers have thought of framework propositions as hinges in a Wittgensteinian hinge epistemology. Under this interpretation, the reasons for pessimism stem from difficulties specific to hinge propositions (or commitments), such as that they are not amenable to rational scrutiny (Pritchard 2018; Ranalli 2018a; Siegel 2019). On the other hand, some philosophers have taken framework propositions to be more like fundamental epistemic principles (Lynch 2010; Kappel 2012; Matheson 2018). The argument for premise 2 is then taken to be an issue over epistemic circularity. Either of these interpretations can be developed in a number of ways, depending on how exactly hinge epistemology, or fundamental epistemic principles are understood. ${ }^{1}$ There has been con-

\footnotetext{
${ }^{1}$ For example, there are two different accounts of hinge epistemology: a nonepistemic theory according to which hinge commitments are outside the scope of rational evaluation, and an epistemic theory, according to which they are but have "warrant" or "entitlement" rather than justification in the standard sense. (C) Leah Henderson Informal Logic, Vol. 40, No. 3 (2020), pp. 359-382
} 
siderable discussion over whether an argument for pessimism about the rational resolvability of deep disagreement can succeed, given some way of filling in the details (Lynch 2010; Kappel 2012; Matheson 2018; Pritchard 2018; Ranalli 2018a; Siegel 2019).

All of this discussion is predicated on the framework proposition reading. However, this is not the only way to interpret Fogelin's pessimistic argument. In section 5, I will spell out another reading of Fogelin's argument, which I suggest captures much of what he was concerned with, and which I think gives a good representation of a way he has commonly been read, particularly by scholars in argumentation theory. I call this the "common ground reading." We will then see that Feldman's reply fails to address this reading at all. Furthermore, I will argue this reading gives rise to several substantial and worthwhile issues, which are of interest in considering Fogelin's argument (section 6).

\subsection{Resolution of a disagreement}

First, let us consider what is meant by resolution of a disagreement. I will argue that Feldman is working with a considerably weaker notion of resolution of disagreement than the notion which is at stake in Fogelin's argument. Feldman understands "resolution of disagreement" purely in terms of achieving agreement or consensus. Feldman argues that this may be achieved when the rational response to the evidence results in both parties coming to share a judgment, or when the rational response requires suspension of judgment because the evidence has become balanced. However, the concern behind Fogelin's argument is arguably more substantive. The core issue here concerns whether people can make progress towards substantive agreement on important matters like abortion or affirmative action by means of rational argument. Another way to put it is: can rational argument be "productive" on these deep questions? (Phillips 2008). In order to understand the notion of "progress" or "productive" here, we need a different notion of resolution of disagreement which involves more than simply the notion of consensus. We need to also talk about the common ground that the parties have. We will say that an argu-

(C) Leah Henderson Informal Logic, Vol. 40, No. 3 (2020), pp. 359-382 
ment is "productive" if it increases the amount of common ground between the parties involved in relevant ways. A "substantial resolution" will be achieved if the parties achieve common ground on all the propositions which are important to the issue at hand.

As Feldman also notes, a disagreement can be considered at different stages, from initial isolation to full disclosure (Feldman 2006a, pp. 219-220). One stage which is of interest is the stage after learning about the disagreement, but before starting to argue with each other. I will refer to this stage as the "beginning of engagement." For Feldman, as we have seen, learning of the disagreement can change the evidential situation, because disagreement is evidence that you are wrong, and the parties involved need to take account of this. However, the beginning of engagement is still far from the stage of full disclosure, which occurs after the parties have engaged in an extensive argument.

Now, according to Feldman's account, the two parties might be rationally required to resolve their disagreement at the beginning of engagement by suspending judgment. However, this does not tell us anything about whether their subsequent argument was productive. It could happen that the subsequent argument makes no progress, so the rationally required attitude at the stage of full disclosure is still suspension of judgment.

Indeed, as Isaac Levi points out, it is helpful to distinguish between two different ways of using the notion of "consensus" (Levi 1985). When two agents find themselves in a disagreement, they may initiate an investigation or discussion to try to resolve it. As Levi says "an early step in such a joint effort is to identify those shared agreements which might serve as the noncontroversial basis of subsequent inquiry" (Levi 1985, p. 145).

This gives us one notion of consensus: the "consensus of the participants at the beginning of inquiry which constitutes the background of shared agreements on which the investigation is initially grounded" (Levi 1985, p. 145). This should be distinguished from the consensus that participants may sometimes achieve as the outcome of inquiry.

On Levi's picture, each agent involved in a disagreement has some corpus of propositions which they take to be certain, and 
which they might say they "know" (Levi 1974). ${ }^{2}$ For example, agent A might take proposition $h$ to be certain. In doing so, she does not regard $\sim h$ as a serious possibility. Agent B, on the other hand, might take $\sim h$ to be certain, and not regard $h$ as a serious possibility. After discovering that they disagree, both agents may revise their commitments by "contraction": that is, by removing propositions from the set to which they are fully committed. Thus, A may contract by removing $h$ and $\mathrm{B}$ may contract by removing $\sim h$. They are both then in the state of shared agreement where their corpus contains neither $h$ nor $\sim h$. This may be seen as a state of "suspension of judgment" regarding the truth of $h$. Such a suspended state would be a consensus at the beginning of engagement, which aimed at identifying shared agreements.

$\mathrm{A}$ and $\mathrm{B}$ may now continue to investigate. They might gather more evidence, swap evidence, or attempt to convince one another with arguments. This process may lead to them both "expanding" their commitments again by adding $h$ (or $\sim h$ ). If they converge in this way, this would be a consensus that they achieve as the outcome of inquiry. It is also possible that nothing further is gained in the process of inquiry, and the consensus achieved at the end of the inquiry does not go beyond the original consensus of shared agreements. $^{3}$

In an example like this, A and B would have "resolved their disagreement," in Feldman's sense, already at the beginning of engagement because they have, at that stage, achieved a common attitude towards the proposition in question. However, this tells us

\footnotetext{
${ }^{2}$ Levi conflates propositions that are known with propositions about which one is certain. Thus, his picture is arguably inconsistent with Wittgenstein's, if we take it that there are some propositions (the hinge propositions) about which we can be certain, without the need to confront them with evidence or to give justifications for them. However, Levi's picture is consistent with Feldman's since Feldman also denies that there are propositions with such special status. For both Levi and Feldman, then, the following disagreement between A and B could be either normal or deep.

${ }^{3}$ Note that Levi also makes the distinction between different senses of consensus in the setting where agents have states of partial belief, or "credal states" (Levi 1974).

(C) Leah Henderson Informal Logic, Vol. 40, No. 3 (2020), pp. 359-382
} 
nothing about whether the argument between A and B produced a more substantial resolution after they had engaged in argument.

In order to characterise the notion of a more substantial resolution, we need more than just a notion of consensus. I will suggest that we also make use of a notion of the "common ground" that the agents share. The common ground of the agents is the content of the shared state that represents their consensus. If two parties have achieved consensus by contracting to a state of suspended judgment over $h$, then their state of consensus has no content. They agree only on the proposition $h \mathrm{v} \sim h$, so their state of agreement is completely non-informative. We will say then that they do not have any common ground regarding $h$. This would contrast with a case where the two agents disagree over $h$, but are both committed to another proposition $g$. Then the consensus of shared agreement that they come to has some content, namely $g$. If the two agents come to a consensus at the end of their argument where they have agreed on $h$, then, again, they have increased their common ground. Their argument has therefore been productive. If they have achieved common ground in relation to the disputed proposition(s), then they have resolved their disagreement in a more substantial sense. I take it that this is the question that Fogelin is concerned with: can substantial resolution be achieved in the sense that the parties arrive, as the result of the argumentative process, at opinions with increased common ground between them? In Feldman's own terms, this is closer to the question of whether the issue (as opposed to the disagreement) can be resolved.

One might object that if suspension of judgment is actually the rationally required attitude, then there is no need for any more substantive notion of resolution of disagreement, even if the issue is not resolved. Feldman says that "where suspension of judgment is the proper result, this is neither an awful outcome nor something that should make the process seem pointless" (Feldman 2005, p. 22).

The investigation will thereby have made a "kind of progress": "One will have learned that one's earlier view depended upon a 
deeper principle that, on reflection, is not well-supported" (Feldman 2005, p. 22). This makes it not a bad thing to find out. ${ }^{4}$

It is true that progress of a sort can be made in coming to an agreement where both parties suspend judgment. This is why the step that Levi describes of trying to form a consensus of shared agreement at the beginning of engagement is one which is often adopted. But we may also reasonably ask whether the argument is productive in a stronger sense. Does it move the participants towards a resolution in the sense of increasing the common ground between them? This is also a very legitimate question, particularly if the hope is for agreement on an attitude which can ground decisions and actions on the issue at hand. And this, I suggest, is the question which is of interest in relation to Fogelin's argument.

\section{Common ground reading of Fogelin's argument}

We have seen that Feldman, like a number of other authors, focuses on trying to see if there is something special about framework propositions, which he treats as effectively isolable propositions. However, there are other readings of Fogelin, which focus much more on developing his point that "when we inquire into the source of a deep disagreement, we do not simply find isolated propositions ("The fetus is a person"), but instead a whole system of mutually supporting propositions (and paradigms, models, styles of acting and thinking) that constitute, if I may use the phrase, a form of life" (Fogelin 1985, p. 9). As we have seen, Feldman brushes this point to the side, saying that he does not really understand what it amounts to (Feldman 2005, p. 19).

The point can be developed in several ways. Several authors have developed Wittgensteinian readings of the point by elaborating on the idea that different forms of life may present obstacles to

\footnotetext{
${ }^{4}$ Scott Aikin similarly argues that there can be a kind of progress in a deep disagreement, even when the issue is not resolved: "Often the progress isn't in the form of getting closer to a resolution, but rather it is identifying the connections between commitments on the various sides, the way the reasons in the debate hang together" (Aikin 2018a).

(C) Leah Henderson Informal Logic, Vol. 40, No. 3 (2020), pp. 359-382
} 
mutual comprehension (Godden 2010; Barris 2018) ${ }^{5}$. These authors bring to bear deep Wittgensteinian concerns about how meaning itself is constituted by the language game in which one is participating.

However, Fogelin's point can also be read in a more mundane way, where the underlying concern is the difficulty that a lack of common ground between the participants in a disagreement may pose to their ability to argue with each other. I will call this the "common ground" reading of Fogelin's argument.

We may reconstruct this as follows:

1. There are situations where people are committed to such different frameworks, hinge propositions, forms of life, etc. that they lack substantial common ground. Call these "deep disagreements."

2. Disagreements where the parties lack substantial common ground are rationally irresolvable.

C. Deep disagreements are rationally irresolvable.

This reading appears to be the way the argument has been understood not only by some of Fogelin's more sympathetic readers (Campolo 2005; Turner 2005), but also by critics (Lugg 1986; Phillips 2008; Kraus 2012). It fits well with Fogelin's emphasis on the idea that argument, or argumentative exchange, is normal when it takes place within a context of broadly shared belief, preferences, and shared procedures (Fogelin 1985, p. 6). The reason for premise 2 is that situations where common ground is lacking are situations where rational argumentation cannot proceed in the normal way.

It is worth noting that the underlying observations behind this argument are not particularly implausible. It is not very controversial that common ground between the participants is helpful in argumentation. ${ }^{6}$ It is also not controversial that there are some

\footnotetext{
5 Although it appears that Fogelin himself immediately backs away from this direction, saying "I think the notion of a form of life is dangerous" (Fogelin 1985, p. 9).

${ }^{6}$ Zarefsky (2012) describes this as "almost a truism in argumentation studies" (p. 179).

(c) Leah Henderson Informal Logic, Vol. 40, No. 3 (2020), pp. 359-382
} 
cases where there is less common ground than others. This already leads to the conclusion that there may be cases where rational argumentation becomes very difficult. It would then not be entirely surprising if there were limiting cases where there is such a lack of common ground that argument, at least of the normal kind, becomes in practice impossible.

Some critics have looked for an argument in Fogelin that deep disagreements are impossible to resolve rationally in principle. ${ }^{7}$ However Fogelin does not speak of impossibility in principle. Rather, in some places, the claim he makes is graded: "to the extent that the argumentative context becomes less normal, argument, to that extent, become impossible" (Fogelin 1985, p. 7). The idea could rather be that a lack of shared resources poses an increasing challenge to effective argumentation, and in some cases, it becomes practically impossible. If rational resolution becomes impossible in practice (though not necessarily in principle), this still prompts the practical question which is the main motivation for Fogelin's argument: namely, how should we approach situations where there is deep disagreement? What should we say about whether argumentative activity, such as we teach in informal logic courses, is really the right approach to take in all disagreement situations? Might there be more effective ways to deal with deep disagreements? At the very least, the thought seems to be, it may be better to simply be honest about what can really be accomplished by rational argumentation.

Feldman's response does not really engage with the common ground version of Fogelin's argument. He does not say anything that takes issue with premise 1 , since he does not deny that situations of deep disagreement may involve a lack of common ground. Nor does he provide any direct argument against premise 2 . In fact, he appears to agree with the idea that effective argument makes use of common ground. In (Feldman 2006b), he criticises newspaper columnist Cal Thomas, who argues against gay marriage by saying that people who do not believe in God have no serious grounds for their moral opinions. One of Feldman's objec-

\footnotetext{
${ }^{7}$ For example, Siegel (2013, p. 16).

(C) Leah Henderson Informal Logic, Vol. 40, No. 3 (2020), pp. 359-382
} 
tions to Cal Thomas is precisely that his arguments become pointless if they do not appeal to shared premises:

It is hard to see the point of arguing about such an issue in a mass circulation public newspaper when you know that your premises are widely disputed among the readers. Good argument proceeds, whenever possible, by appeal to shared premises (Feldman 2006b, p. 2).

One might think, however, that Feldman's response does implicitly amount to a denial of premise 2 . He offers a procedure for resolving any disagreement, even a deep one, by rational evaluation of the evidence at each stage, which does not appear to have any necessary conditions in terms of common ground. Again, however, the plausibility of the apparent lack of requirements may depend on the weak notion of resolution that he employs. The less that is required of a resolution, the fewer requirements there will be on the process that gets you to resolution. There may indeed not be so many requirements on an argumentative process if you only want resolution in the sense of removing the disagreement. If you are aiming for a more substantial resolution, the requirements may be considerably more stringent. Feldman has not said anything to eliminate the possibility that some kind of common ground as a starting point is a requirement for substantial resolution, perhaps not in an absolute sense, but in any realistic practice. Indeed, he says very little about the nature of the process by which argument proceeds - treating it simply as an exchange of evidence. Even here, as other authors have also pointed out, it is not necessarily straight-forward to assume, in cases of deep disagreement, that there is an unequivocal notion of "evidence" which it is legitimate to appeal to (Godden 2010). This is part of the challenge that Fogelin's argument raises.

\section{The real issues raised by Fogelin's common ground argu- ment}

The common ground version of Fogelin's argument does raise important and interesting issues, several of which are already discussed in the literature. 
One set of issues concerns the first premise. What are the minimal requirements on common ground for rational argumentation? Fogelin has argued that "normal" rational argumentation requires substantive shared resources. One strategy for tackling Fogelin then is to consider whether there might be less "normal," but still rational, modes of argument that do not rely on possession of such substantial common ground between the participants. Dana Phillips has suggested, for instance, that arguments can be profitably pursued without any common ground in terms of shared beliefs and preferences as long as there is a certain shared commitment to procedural norms of argumentation (Phillips 2008). Andrew Lugg suggests that appealing to shared ground is only one way to make a rational argument:

The strategy of reverting to neutral ground is only one strategy among many. Individuals can also bring about a shift in one another's allegiances by demonstrating hidden strengths of their own views and by elicting hidden weaknesses of alternative views. Furthermore, they may find themselves having to shift ground as a result of their discovering things wrong with the views they accept and things right with the ones that they reject (Lugg 1986, p. 48).

Lugg points to a number of alternative practices that he takes to be effective routes to resolution, including disentangling ideas, coordinating and systematising, marshalling reasons, isolating suspect assumptions, reviewing alternative proposals and negotiating conflicting demands (Lugg 1986, p. 49). Other authors have pointed to alternative conceptions of rational argumentation which emphasise the role of third parties. Manfred Kraus, for example, appeals to an ancient art used by the sophists of 'arguing contradictorily' by consciously setting opposing sides alongside each other in competition, even if they have little in common (Kraus 2012). Such practice can have the function of clarifying the competing positions for an audience who witnesses the dispute. ${ }^{8} \mathrm{~A}$ variety of rhetorical strategies for making progress in deep disagreements have also been explored (Zarefsky 2012). One might, for instance, attempt to argue from the other person's point of

\footnotetext{
${ }^{8}$ Similar ideas about the role of third parties are found in Memedi (2007).

(C) Leah Henderson Informal Logic, Vol. 40, No. 3 (2020), pp. 359-382
} 
view by deploying premises that you do not yourself accept. A key question for any of these approaches is whether the proposed moves do actually count as forms of rational argumentation, as opposed to forms of "persuasion." After all, for Fogelin, the alternative to persisting with a form of rational argument in situations where it is ineffectual was also to use techniques of persuasion. ${ }^{9} \mathrm{~A}$ worthwhile upshot of Fogelin's argument then is that it has stimulated discussion about what sorts of activities can be most beneficial in genuine attempts to resolve deep disagreement, and at the same time it has provoked an exploration of the dangers and benefits of rational argumentation in different contexts.

Another set of issues concerns the first premise. Are there ever really situations where sufficiently substantial common ground is missing? Is there not some level — perhaps a more general levelat which people can find common ground even on matters of value? Although this may be true, the question that is relevant to Fogelin's argument is whether the disagreeing parties can access their common ground in a way which makes it available for use in argumentation. Situations of deep disagreement do seem to be ones where the identification of common ground can be particularly difficult (Phillips 2008). Not all our commitments may be transparent to us, particularly when they concern very fundamental beliefs and values, so it can be hard to extract these for the purposes of lining them up with the commitments of another. And this is made even harder by the entanglement of these commitments in a whole system of propositions, as will typically be the case in a deep disagreement. Even if common ground does exist, then, it may be difficult to identify it in these sorts of situations. Some authors have suggested that simply pursuing the usual procedures of arguing will result in the common ground being suitably brought to the surface (eg., Lugg 1986; Siegel 2013). However, pursuing argumentation with the aim of persuasion may not be the only, or the most, effective way of finding common ground. More

\footnotetext{
${ }^{9}$ For example, Peter Davson-Galle critiques Lugg's suggestions by arguing that a number of the alternative forms of rational argument are actually not rational in the sense of "reason-giving," but should instead be thought of as persuasion techniques (Davson-Galle 1992).

(C) Leah Henderson Informal Logic, Vol. 40, No. 3 (2020), pp. 359-382
} 
in-depth analysis of the processes that lead to the identification of common ground and the conditions that make them effective seems to be in order.

\section{Conclusion}

Fogelin's argument raises the important question of what the role of critical thinking and rational argument should be in dealing with deep disagreements. The argument can be interpreted, broadly speaking, in two ways. On the one hand, it can be taken to be driven by the claim that deep disagreements involve special kinds of propositions (framework propositions, Wittgensteinian hinges, fundamental epistemic principles) which frustrate normal means of argumentative resolution. Or, it may be driven by pessimism about how effective the practice of rational argumentation is in situations where the participants lack common ground.

Feldman's reply is based on the first kind of interpretation. He attempts to undermine the idea that framework propositions present any special obstacle to the resolution of disagreement. But even if he is right about this, the positive part of his argument succeeds only in establishing that deep disagreements can be rationally resolved in a weak sense, not in the sense which was the focus of Fogelin's argument.

Furthermore, Feldman's reply does not engage with the second type of interpretation of Fogelin's argument. According to this interpretation, the argument primarily concerns the role of common ground in argumentative practice, and the main point is that since argumentation normally makes use of common ground as a kind of resource, it may be crippled when that resource is lacking. This interpretation raises substantive issues which are well worth considering, and which a number of authors have discussed. Are there types of argumentative practice which are "rational," but which do not rely on possession of common ground? And what exactly does the common ground look like when parties are deeply divided by their fundamental commitments? 


\section{Acknowledgements}

Thanks to Jan Albert van Laar, Erik Krabbe, and Daan Evers for their helpful comments on a draft of this paper. I acknowledge support from a Veni grant (275-20-058) from the Dutch Science Foundation (NWO).

\section{References}

Aikin, Scott F. 2018a. Deep disagreement and the problem of the criterion. Topoi.

Aikin, Scott F. 2018b. Deep disagreement, the dark enlightenment, and the rhetoric of the red pill. Journal of Applied Philosophy 36(3): 420-435.

Barris, Jeremy. 2018. Deep disagreement and the virtues of argumentative and epistemic incapacity. Informal Logic 38(3): 369-408.

Campolo, Christian. 2005. Treacherous ascents: on seeking common ground for conflict resolution. Informal Logic 25(1): 37-50.

Davson-Galle, Peter. 1992. Arguing, arguments, and deep disagreements. Informal Logic 14(2\&3): 147-156.

Feldman, Richard. 2005. Deep disagreement, rational resolutions and critical thinking. Informal Logic 25(1): 13-23.

Feldman, Richard. 2006a. Epistemological puzzles about disagreement. In Epistemology futures, ed. Stephen Hetherington. Oxford: Oxford University Press.

Feldman, Richard. 2006b. Reasonable religious disagreements. In Philosophers without Gods: meditations on atheism and the secular life, ed. Louise Anthony, 194-214. Oxford: Oxford University Press.

Feldman, Richard. 2009. Evidentialism, higher-order evidence, and disagreement. Episteme 6(03): 294-312.

Fogelin, Robert. 1985. The logic of deep disagreements. Informal Logic 7: 1-8.

Godden, David M. and William H Brenner. 2010. Wittgenstein and the logic of deep disagreement. Cogency 2(2): 41-80. 
Kappel, Klemens. 2012. The problem of deep disagreement. Discipline Filosofiche 22(2): 7-25.

Kraus, Manfred. 2012. Cultural Diversity, cognitive breaks, and deep disagreement. In Topical Themes in argumentation theory, 22, eds., Frans H. van Eemeren and Bart Garssen, 91-107. Dordrecht Heidelberg London New York: Springer.

Levi, Isaac. 1974. On indeterminate probabilities. Journal of Philosophy 71(13): 391-418.

Levi, Isaac. 1985. Consensus as shared agreement and outcome of inquiry. Synthese 62(1): 3-11.

Lugg, Andrew. 1986. Deep disagreement and informal logic: no cause for alarm. Informal Logic 8: 47-51.

Lynch, Michael P. 2010. Epistemic circularity and epistemic incommensurability. In Social Epistemology, Adrian and Millar Haddock, Alan and Pritchard, Duncan. Oxford: Oxford University Press.

Matheson, Jonathan. 2018. Deep disagreements and rational resolution. Topoi.

Memedi, Vesel. 2007. Resolving deep disagreement. Paper presented at the Dissensus and the search for common ground, Windsor, ON.

Phillips, Dana. 2008. Investigating the shared background required for argument: a critique of Fogelin's thesis on deep disagreement. Informal Logic 28(2): 86-101.

Pritchard, Duncan. 2018. Wittgensteinian hinge epistemology and deep disagreement. Topoi.

Ranalli, Chris. 2018a. Deep disagreement and hinge epistemology. Synthese. doi:10.1007/s11229-018-01956-2

Ranalli, Chris. 2018b. What is deep disagreement? Topoi 1(3).

Siegel, Harvey. 2013. Argumentation and the epistemology of disagreement. OSSA Conference Archive 157: 1-22.

Siegel, Harvey. 2019. Hinges, disagreements, and arguments: (rationally) believing hinge propositions and arguing across deep disagreements. Topoi. doi:10.1007/s11245018-9625-6 
Turner, Dale and Larry Wright. 2005. Revisiting deep disagreement. Informal Logic 25(1): 25-35.

Zarefsky, David. 2012. The appeal for transcendence: a possible response to cases of deep disagreement. In Topical themes in argumentation theory, eds. Frans $\mathrm{H}$. van Eemeren and Bart Garssen, 77-89. Dordrecht: Springer. 